\title{
Performance of a groyne in controlling flow, sediment and morphology around a tributary confluence
}

\author{
Kohji Michioku, ${ }^{1,}$, Yuki Osawa ${ }^{2}$, and Keiichi Kanda ${ }^{3}$ \\ ${ }^{1}$ Hosei University, 2-33 Ichigaya-Tamachi, Shinjuku, Tokyo 162-0843, Japan \\ 2 Tokyu Corporation, 5-6 Nanpeidaicho, Shibuya, Tokyo 150-8511, Japan \\ ${ }^{3}$ National Institute of Technology, Akashi College, Uozumi, Akashi 674-8501, Japan
}

\begin{abstract}
In a middle stream reach, irreversible morphological changes are observed such as growth of a huge sandbar in front of the confluence, thalweg migration from the left to right bank, erosion of the main channel and sedimentary deposit on the floodplain. As a countermeasure against such degradation of river morphology, a groyne was constructed beneath the tributary confluence. Performance of a groyne in controlling flood flow, sediment transport and river morphology was investigated by a twodimensional hydrodynamic model. The analysis on twenty years of morphological change indicates that the groyne has an excellent performance in improving quality of river morphology such as reduction of the sandbar development and migration of the thalweg to the original position.
\end{abstract}

\section{Introduction}

Anthropogenic river regulation for flood management and water use brought significant degradation of landscape, biodiversity and other ecological quality of rivers in the past few decades. The key issue for a comprehensive river management is to properly understand the complex interrelating mechanism between hydrodynamics, fluvial processes and ecosystem [1]. The flow is dominated not only by artificial structures, but also by geomorphology. During a severe flood flow, interaction between flow and sediment transport causes significant evolution of geomorphology and brings irreversible damage not only of structures but also of ecosystem. This, in turn, causes marked impacts on hydraulic and fluvial processes.

Studies have extensively been carried out in order to investigate hydrodynamic impacts of river control structures such as weirs, barrages, dams, groynes, spurs, etc. on fluvial and ecological systems in rivers [2], [3]. Many researchers recently focused their attention on impacts of morphological and sedimentological processes on fauna and flora in rivers from the viewpoints of engineering, limnology and ecology [4], [5]. In addition, field and numerical studies were carried out regarding sedimentation around confluence, which is another focal issue in this study [6].

*Kohji Michioku: kohji.michioku.47@hosei.ac.jp 


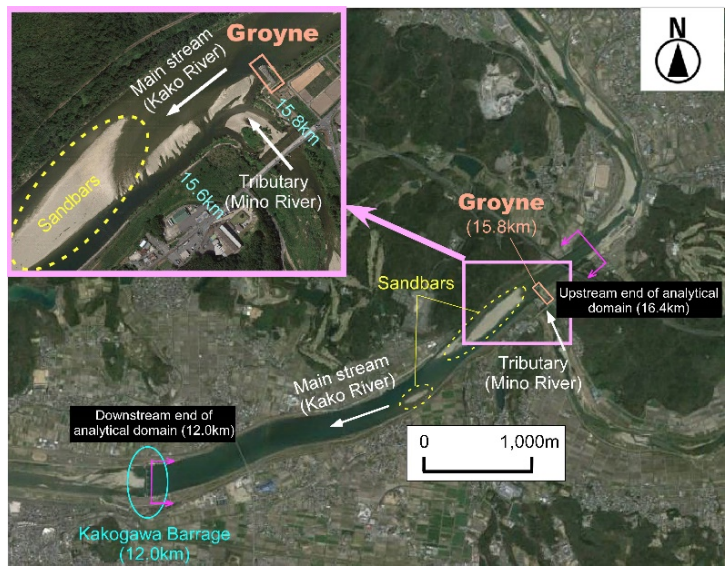

Fig. 1. Study field.

The field site is a reach between $12-18 \mathrm{~km}$ from the river mouth of Kako River, a first class river in Japan. As shown in Figure 1 a major tributary Mino River perpendicularly joins the main stream and the flow is strongly influenced by the back water stretched from the Kakogawa Barrage located downstream. The barrage was constructed for irrigation, city water and flood control in 1987. It is considered that the water impounded by the barrage predominantly affects hydro- and morphodynamics in the upstream reach, which has brought a significant change in fluvial process around the confluence in the last two and a half decades after construction of the barrage.

Typical irreversible morphological changes which appeared in the reach are overgrowth of a sandbar in front of the confluence, thalweg migration from the left to right bank, erosion of the main channel and sedimentary deposit on the floodplain. Such a morphological regime shift brings serious issues not only in flood control and management but also in ecosystem and hydrophilic activities. As a countermeasure against the morphological degradation, a groyne was installed at the left bank upstream of the confluence in 2014 as shown in Figure 1. This is a concrete block mound structure $44 \mathrm{~m}$ long and $6 \mathrm{~m}$ high and installed perpendicularly to the flow direction. It is expected that the groyne would function as a trigger to change morphodynamics so that the river channel is restored to its original state. However, it is not yet known at this moment if the groyne could improve and rejuvenate the river in the future as we expect. The present study is to discuss performance of a groyne in controlling flood flow, sediment transport and river morphology. It was numerically investigated how dimensions, orientation and location of groyne affect flood flow structure and river morphology by using a hydrodynamic model.

\section{Summary of hydrodynamic analysis}

In order to examine the effects of the groyne properties on flood flows and river morphology, a two-dimensional shallow flow model was applied to analyse hydrodynamic and fluvial processes during flood events. The numerical computation for flood routing was done for various length, height, orientation and location of the groyne. The solver is a Nays2DH provided from the "iRIC (international River Interface Cooperative) Software" [7]. The analytical domain is a $6 \mathrm{~km}$-long reach stretching from the barrage, through the confluence of Mino River to the straight reach at $16.4 \mathrm{~km}$. The bathymetry of river channel was generated from the dataset surveyed by the Ministry of Infrastructure, Transportation and Tourism, MLIT in 1991. Water levels and discharges were recorded at the two stream gauging stations, Ohshima $(20.0 \mathrm{~km})$ and Kunikane $(14.2 \mathrm{~km})$, which provide individual 


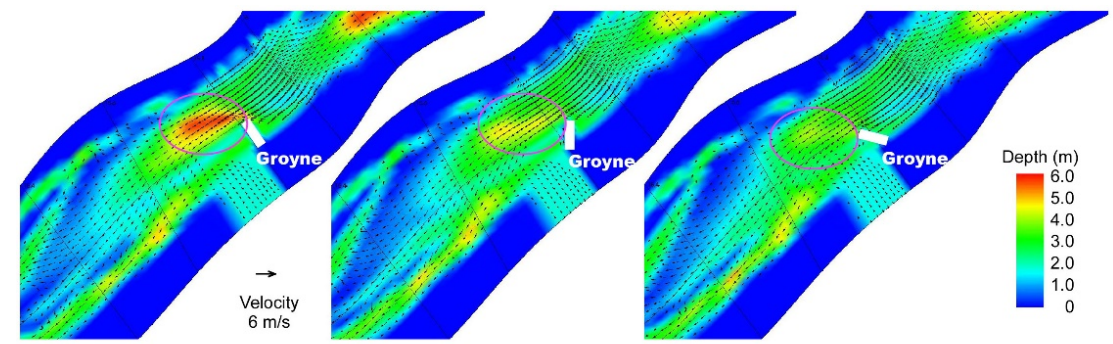

(a) Groyne perpendicular to the shoreline (b) Groyne pointing upstream

(c) Groyne pointing downstream

Fig. 2. River bed profiles after the flood in September, 2011.

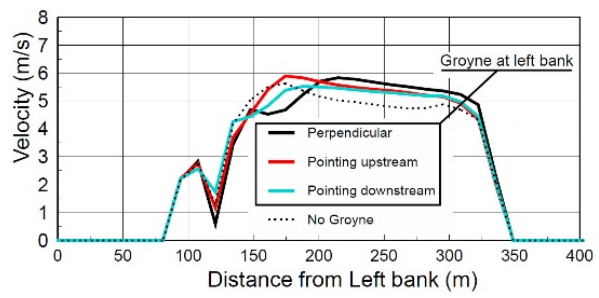

Fig. 3. Velocity profiles at peak discharge in the cross section of $15.6 \mathrm{~m}$.

discharges into Kako and Mino Rivers, respectively. The field data gives boundary conditions for the present analysis. The numerical domain was divided into 30 elements in the crosswise direction and the mesh size in the streamwise direction was typically $\Delta x$ $=10 \mathrm{~m}$. Numerical integration was conducted with time step $\Delta t=0.1 \mathrm{~s}$. A $600 \mathrm{~m}$ long approaching reach with a uniform cross section was attached to the upstream boundary in order to give stable boundary conditions both of discharge and sediment loading rate. In order to generate an initial condition, a preliminary steady flow analysis was carried out for one hour.

Two analyses were carried out, i.e. a short duration analysis for a single flood event and a long duration analysis by assuming a sequence of flood events which occurred in the last twenty years. The objective of the short duration analysis was to fundamentally understand how the groyne influences morphodynamics during a flood. The long duration analysis was performed to examine impacts of the groyne on years-long fluvial process and morphology.

\section{Short duration analysis}

The flood event analysed was the one which occurred in September 2011, the second largest event in the last half century [8]. Hydrographs in the main channel and the tributary are given as boundary conditions in the flood routing. The analysis was carried out for various height, length, orientation and location of the groyne. The present groyne that is perpendicularly installed to the shoreline is also analysed as a reference case.

\subsection{Effect of groyne orientation}

Contours in Figure 2 are the river bed profiles after the flood, for the different groyne orientation, i.e. groyne perpendicular to the flow direction, groyne pointing upstream and groyne pointing downstream. Erosion in front of the groyne head marked by a circle is most significant in the case when the groyne is perpendicularly arranged to the shoreline. 


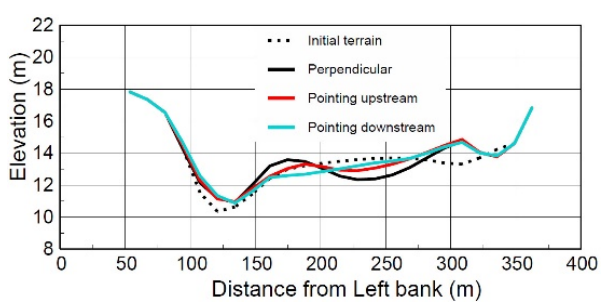

(a) Groyne at left bank

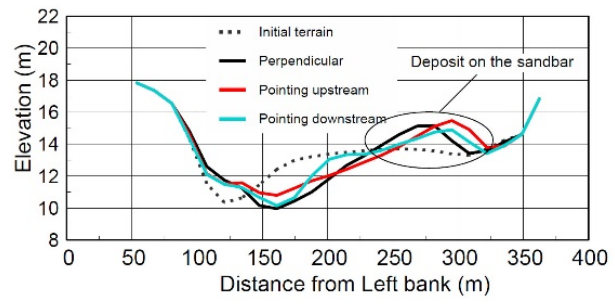

(b) Groyne at right bank

Fig. 4. Bed elevation profiles at peak discharge in the cross section of $15.6 \mathrm{~m}$.

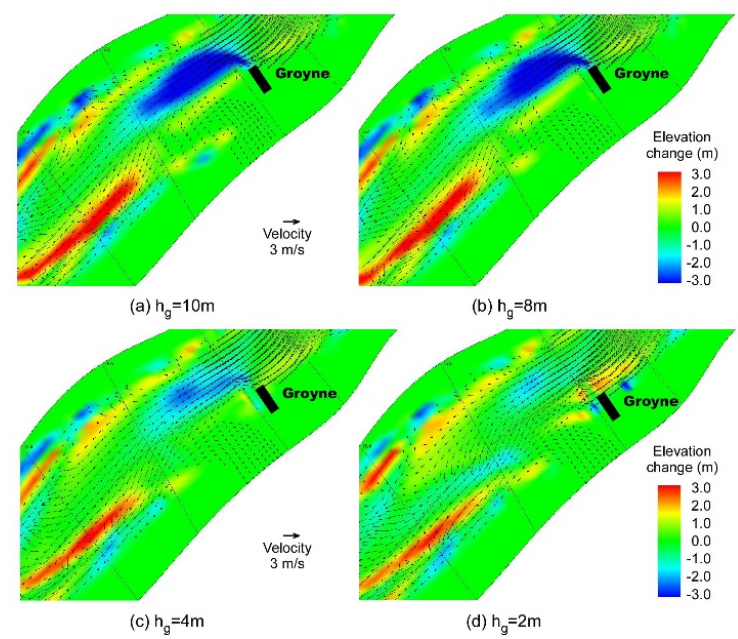

Fig. 5. Bed elevation change after the flood for various groyne height.

The erosion is smallest for the groyne pointing downstream. In the further downstream reach, the morphology is not significantly influenced by the groyne. Figure 3 indicates velocity profiles at the peak discharge in a cross section of $15.6 \mathrm{~m}$ that is about $200 \mathrm{~m}$ downstream from the groyne. By comparing the cases, the perpendicularly arranged groyne most successfully pushes the main current away from the bank.

\subsection{Effect of groyne location}

In Figure 4, bed elevation in the cross section at $15.6 \mathrm{~m}$ after the flood is compared among six cases of different orientation and location of groyne. The river bed profile is dominated more by location rather than by orientation. In cases when the groyne was installed at the right bank, more sediment tends to be deposited on the sandbar which has already grown in front of the confluence. This means that the sandbar would continue to grow and the present thalweg would eventually be more eroded if the groyne was constructed at the right bank. Fortunately, it was not.

\subsection{Effect of groyne height}

Let us pay attention to the case of the groyne perpendicularly installed to the flow direction. Bed elevation change around the confluence after the flood is demonstrated in Figure 5 for four different heights of the groyne, where height of the present groyne is $h_{\mathrm{g}}=6 \mathrm{~m}$. The scour hole more significantly develops in front of the groyne head in the case of higher groyne. On the other hand, the hole grows less in the case of lower groyne. 


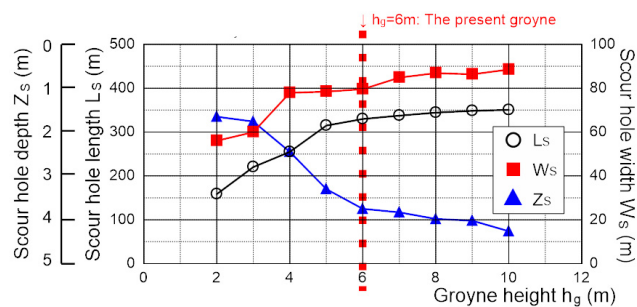

(a) dependency on $h_{\mathrm{g}}$

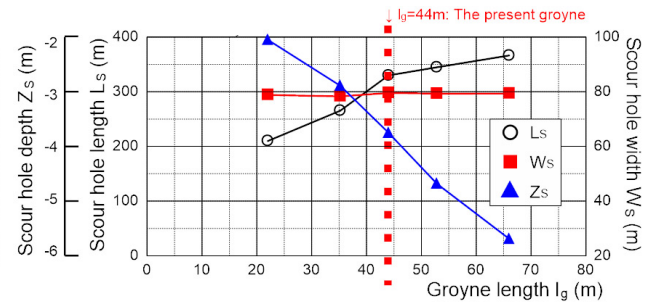

(b) dependency on $l_{\mathrm{g}}$

Fig. 6. Scour hole dimensions as functions of groyne height $h_{\mathrm{g}}$ and length $l_{\mathrm{g}}$. $\left(L_{\mathrm{S}}, W_{\mathrm{S}}, Z_{\mathrm{S}}\right)$ are length, width and maximum depth of the scour hole, respectively.

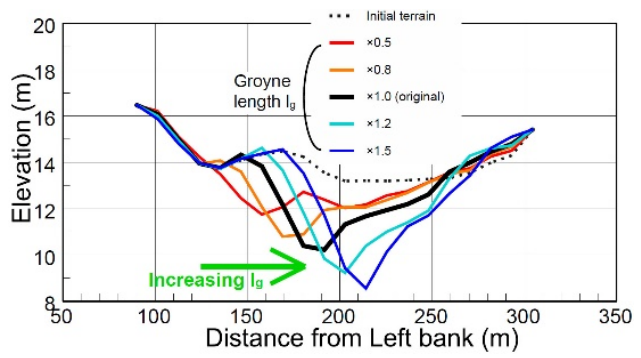

Fig. 7. Bed profiles after the flood for various length of the groyne $l_{\mathrm{g}}$ (at $15.6 \mathrm{~km}$ ).

Geometrical parameters of the scour hole is summarized in Figure 6(a) in which length, width and maximum depth of the hole $\left(L_{\mathrm{S}}, W_{\mathrm{S}}, Z_{\mathrm{S}}\right)$ are plotted as functions of the groyne height $h_{\mathrm{g}}$. The present groyne is $6 \mathrm{~m}$ in height as mentioned before and marked in a red dotted line in the figure. The figure demonstrates that the scour hole or fluvial process is less independent on the groyne height when the groyne was higher than the present one. In other words, the present groyne has the most appropriate and minimum height for changing the morphology.

\subsection{Effect of groyne length}

In Figure 7, the bed elevation profiles after the flood at $15.6 \mathrm{~km}$ are compared among cases with various lengths of the groyne $l_{\mathrm{g}}$. The results are demonstrated only for the cases of the groyne that is perpendicularly installed at the left bank shore. With increasing $l_{\mathrm{g}}$, location of the scour hole tends to be formed away from the shore and the hole becomes deeper. In the same manner as Figure 6(a), correlations between $\left(L_{\mathrm{S}}, W_{\mathrm{S}}, Z_{\mathrm{S}}\right)$ with $l_{\mathrm{g}}$ are plotted in

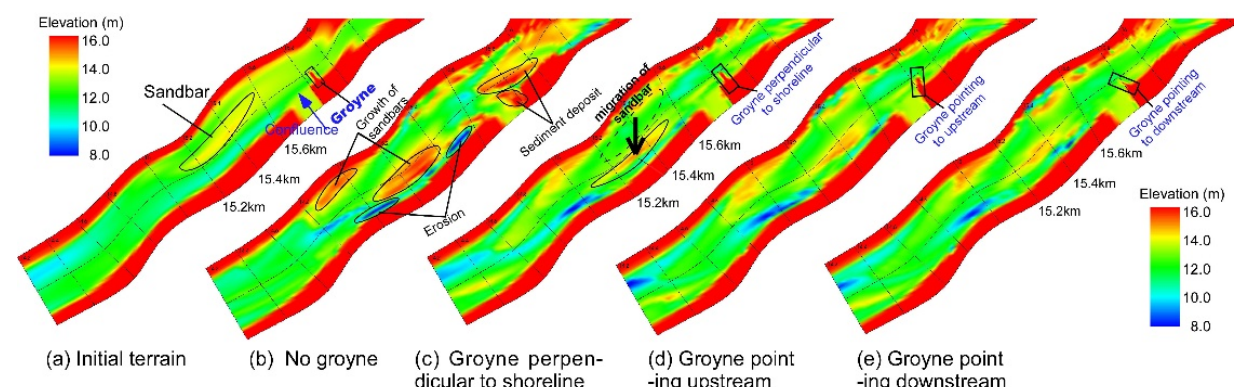

Fig. 8. River bed profiles formed after the flood events during twenty years. The results are shown for various groyne orientations. The groyne has the same dimension as the present one, i.e. $h_{\mathrm{g}}=6.0 \mathrm{~m}$ and $l_{\mathrm{g}}=44 \mathrm{~m}$. 


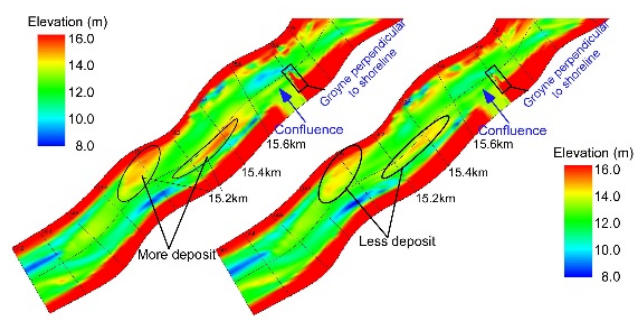

$\begin{array}{ll}\text { (a) } h_{g}=8.0 \mathrm{~m} & \text { (b) } \mathrm{h}_{\mathrm{g}}=4.0 \mathrm{~m}\end{array}$

(A) $h_{\mathrm{g}}=8.0$ and $4.0 \mathrm{~m}$ (cf. Fig. $8(\mathrm{c})$, i.e. $h_{\mathrm{g}}=6.0 \mathrm{~m}$ ).

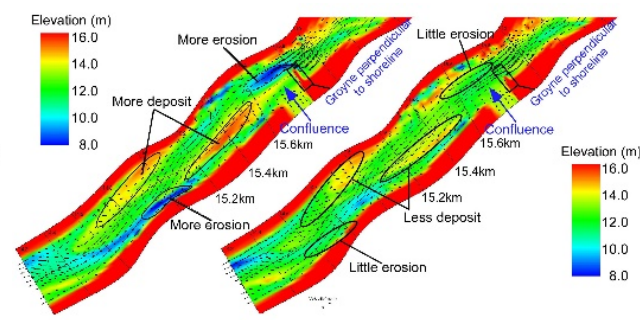

(a) $\left.\right|_{g}=66 \mathrm{~m}$

(b) $\mathrm{I}_{\mathrm{g}}=22 \mathrm{~m}$

(B) $l_{\mathrm{g}}=66.0$ and $22.0 \mathrm{~m}$ (cf. Fig. 8 (c), i.e. $\left.l_{\mathrm{g}}=44.0 \mathrm{~m}\right)$.

Fig. 9. River bed profiles after the floods for different groyne height and lengh.

Figure $6(\mathrm{~b})$, where dimensions of the present groyne are marked in the diagram. It is recognized that the hole becomes deeper and longer with $l_{\mathrm{g}}$. However, its width $W_{\mathrm{S}}$ is almost independent of $l_{\mathrm{g}}$.

\section{Long duration analysis}

\subsection{Computational conditions}

A twenty-year long analysis was performed by assuming a sequence of flood discharge recorded during 1992-2011[8]. Since a much longer computational time is required compared to the short duration analysis, only twelves cases of groyne geometry were examined. The case with no groyne was also examined as a reference case.

\subsection{Effect of groyne orientation}

Figure 8 shows the river bed profile formed after the flood events during the twenty years, where the results from various groyne orientations are compared. In the absence of the groyne in Figure 8(b), considerable amount of bed materials are piled up around the confluence, the sandbars are overgrown and the thalweg tends to be eroded. Quality of the river morphology declines very significantly in this manner, if no groyne is installed. On the other hand, such morphological degradation is prevented by the groyne almost independently of its orientation as seen in Figure 8(c), (d), (e).

\subsection{Effect of groyne height and length}

Effect of the groyne height on river morphology is rather limited as seen in Figures 8(c) and 9(A), where the bed elevation profiles after twenty years are compared among the three cases of groyne height with the present one. In Figure 9(B) the bed elevation profiles are compared between the cases of groyne length with 1.5 and 0.5 times of the present one. As marked in Figures 9(B) and 8(c), erosion in front of the groyne head and growth of sandbar are more significant for the longer groyne.

\subsection{Discussion on performance of a groyne in regulating river morphology}

\subsubsection{Conveyance capacity}

From a viewpoint of flood control, it is worthwhile to investigate the performance of a groyne in controlling flow conveyance capacity of the channel. Here, change in the cross 


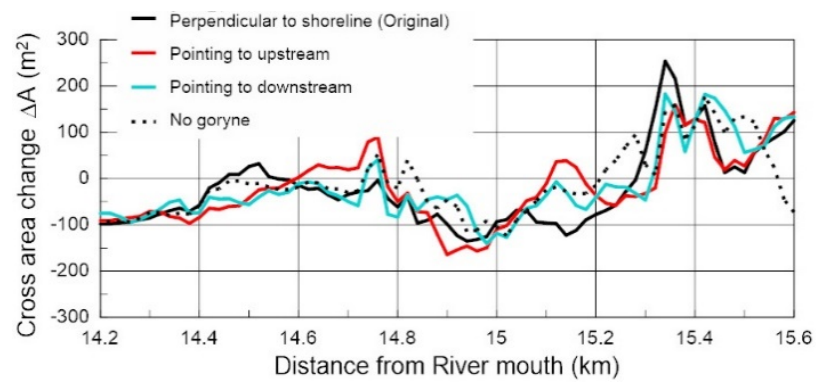

Fig. 10. Change in the cross section area after the floods during twenty years $\Delta A$.

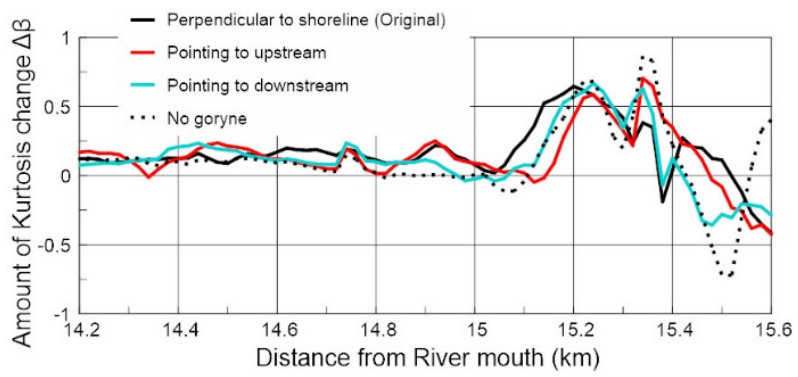

Fig. 11. Change in kurtosis of bed elevation profile after the floods, $\Delta \beta$.

section area after the twenty years $\Delta A$ is examined as an index of the conveyance capacity improvement. $\Delta A$ is estimated from the river bed profiles before and after the twenty-year long flood events.

Figure 10 demonstrates longitudinal profiles of $\Delta A$ between $x=14.2-15.6 \mathrm{~km}$ which is a $1.4 \mathrm{~km}$-long reach located at the downstream side of the confluence. In the figure, the results of the four cases of groyne orientation are compared, i.e. the groyne perpendicular to the shore, pointing to upstream, pointing to downstream and no groyne. The cross section area between $15.2-15.6 \mathrm{~km}$ are changed rather than in the other parts of reach in every case of groyne orientation, where the fluvial process in this reach is considerably dominated by the tributary confluence as well as by the groyne. The positive value of $\Delta A$ in this reach means that the river bed is eroded, which eventually increases the flow conveyance capacity. On the contrary, the cross section area scarcely changes downstream further than $14.4 \mathrm{~km}$. This is a reservoir area dammed up by the barrage and the river morphology is much less influenced either by the confluence or by the groyne. In the reach between 14.8$15.2 \mathrm{~km}, \Delta A$ takes a small negative value, which is a tendency of fluvial process commonly observed in every case of groyne orientation.

\subsubsection{Quality of river morphology}

From an ecological point of view, morphological trends such as erosion of thalweg, sedimentation on floodplain, sandbar overgrowth, etc. most possibly invite morphological bipolarization and frequently cause deterioration in ecomorphological quality. In this section, the kurtosis of bed elevation profile in a cross section $\beta$ is introduced as a parameter indicating quality of river morphology. According to its definition, the river morphology tends to become polarized by decreasing the kurtosis. Therefore, in order to create a morphologically and ecologically sustainable river, a wise and proper management is required to keep the channel morphology a certain level of kurtosis. 
Change in kurtosis before and after the twenty years, $\Delta \beta$, is plotted in Figure 11 for various groyne orientations. Positive and negative values of $\Delta \beta$ respectively correspond to improvement and degradation of the channel morphology. In the reach between 15.2$15.6 \mathrm{~km}$ where both confluence and groyne dominate the fluvial process, longitudinal fluctuation of $\Delta \beta$ is significant in all cases. Attention should be paid to the fact that $\Delta \beta$ between 15.4-15.6km turns from negative to positive by installing the groyne, which indicates performance of a groyne in improving the quality of channel morphology. Although only a small difference is recognized in $\Delta \beta$ between $15.0-15.6 \mathrm{~km}$ among the four cases, the groyne perpendicular to the shore shows a slightly better performance than the others. The groyne pointing downstream demonstrates the least positive performance among them. In downstream further than $15.0 \mathrm{~km}$ or in the back water reach stretched from the barrage, little difference is found among the four cases of groyne.

\section{Concluding remarks}

Groyne performance in controlling flood flow, sediment transport and river morphology was investigated in a middle stream reach. A major tributary perpendicularly joins the main stream there and the flow is influenced also by the back water stretched from a barrage at $4 \mathrm{~km}$ downstream. The analysis on twenty years of morphological change demonstrates that the sandbar developing in front of the confluence shrank, the thalweg tends to return to the original position and eventually the geomorphological quality was improved by the groyne. On the other hand, the sandbar was found to grow more and the channel' quality declined if the groyne was constructed on the right bank side. It was also verified that the geomorphology was scarcely influenced by the groyne orientation, while erosion of thalweg and sedimentation on floodplain were well regulated by the groyne. Time-development of two parameters, i.e. area and kurtosis of the bed profile in cross sections, was estimated for various arrangements of groyne in order to examine the performance of a groyne in maintaining channel's conveyance capacity and creating ecologically desirable bathymetry. From the viewpoints not only of controlling floods but also of preserving the natural environment, the present study provides scientific findings useful for a proper river management by installing structures such as groynes and spurs.

The present study was financially supported by the Grant-in-Aid for Scientific Research (C) (Project No. 17K06588, Leader: Kohji Michioku)

\section{References}

1. A. Radecki-Pawlik et al., Open Channel Hydraulics, River Hydraulics Structures and Fluvial Geomorphology (CRC Press, Taylor \& Francis Group, 2017)

2. H. Bokuniewicz, Annals of the New York Academy of Sciences, 17, 51-56, (1994)

3. F. K. Ligon, W. E. Dietrich, W. J. Trush, BioScience, 45, 183-192, (1995)

4. D. J. Gilvear, Geomorphology, 31(1-4), 229-245 (1999)

5. J. M. Wheaton, G. B. Pasternack, J. E. Merz, J. of River Basin Management, 2, 3-20 (2004)

6. S. Rice, A. Roy, B. Rhoads, River Confluences, Tributaries and the Fluvial Network, (John Wiley and Sons Ltd, 2008)

7. Web Site of iRIC, http://i-ric.org/en/software/?c=17, (2017)

8. T. Okuyama, K. Michioku, K. Kanda and S. Kometani, Proc. 11th Intnl. Conf. HydroScience and Eng., 633-641 (2014) 